Vesna Bižić-Omčikus

Etnografski muzej u Beogradu

Srbija

DOI: https://doi.org/10.18485/slovenika.2017.3.1.6

UDK: 069.02:39(497.11)

069.02:39(497.4)

316.7(497.4:497.11)

Stručni rad

\title{
Srbija u SEM-u, Slovenija u EM-u
}

Sažetak

U tekstu Srbija u SEM-u, Slovenija u EM-u objašnjene su migracije predmeta iz Srbije, onih koji se nalaze $u$ Slovenskom etnografskom muzeju $u$ Ljubljani, kao i predmeta iz Slovenije koji se nalaze u Etnografskom muzeju u Beogradu. Kao i ljudi, i predmeti su se zajedno sa svojim vlasnicima selili u razne krajeve Evrope i sveta, pa tako i iz Slovenije u Srbiju i iz Srbije u Sloveniju. Došavši u novu sredinu, oni su od privatnog vlasništva, putem poklona ili otkupa, postajali deo muzejskih zbirki, odnosno, kulturna dobra dostupna javnosti. Kretanjem predmeta prožimale su se kulture naroda koji su ih izradili, a ulaskom u muzeje su ti predmeti postali predstavnici svojih kultura i naroda u novim sredinama.

Ključne reči: Srbija, Slovenija, Etnografski muzej u Beogradu, Slovenski etnografski muzej, etnografska kulturna dobra, predmeti

\section{Uvod}

Od nastanka sveta ljudi putuju, napuštaju mesta svog rođenja, sele se u krajeve gde im se čini da će im život biti udobniji, lakši, lepši ili bolji. Razlozi selidbe mogu biti poslovne ili lične prirode. Napuštajući jedno mesto radi odlaska $u$ drugo, zajedno sa ljudima odlaze i stvari koje su im potrebne ili drage. U nekom trenutku vlasnici ili naslednici požele da se odvoje od tih predmeta, ali tako što ih poklone muzejima, ili ih pak muzeji otkupe. Na taj način oni postaju dostupni stručnjacima za istraživanje, a široj javnosti - za upoznavanje s kulturom naroda iz koga su potekli i sredine iz koje su došli.

Takav je slučaj i sa predmetima srpskog porekla koji se nalaze u Slovenskom etnografskom muzeju u Ljubljani, a i sa predmetima slovenačkog porekla koji se nalaze $u$ Etnografskom muzeju $u$ Beogradu. Preseljenja etnografskih kulturnih dobara iz navedenih 
područja počela su dvadesetih godina XX veka, kada su postojali intenzivna saradnja i prijateljstvo prvog upravnika Etnografskog muzeja u Beogradu dr Sime Trojanovića i prvog upravnika Slovenskog etnografskog muzeja dr Nika Zupaniča. U manjem obimu, ova kulturna prožimanja nastavila su se tridesetih i šezdesetih godina XX veka, da bi prestala krajem XX veka. Međutim, iako je saradnja ova dva muzeja bila zastala, ona se nastavila $u$ XXI veku: u periodu od 4. do 30. jula 2017. godine Slovenski etnografski muzej gostovao je u Etnografskom muzeju u Beogradu sa izložbom „Dr Niko Zupanič, kosmopolita iz Bele Krajine“.

\section{„Srbija“ u Slovenskom Etnografskom muzeju u Ljubljani}

U Ljubljani, u Slovenskom etnografskom muzeju postoji zbirka etnografskih predmeta poreklom iz Srbije, od kojih najveći broj potiče iz vremena kada je dr Sima Trojanović bio upravnik Etnografskog muzeja u Beogradu. Naime, pre nego što je postao upravnik Muzeja, Sima Trojanović je u Minhenu, u okviru svojih specijalističkih studija iz muzeologije, pohađao i predavanja iz fizičke antropologije, koju je studirao Niko Zupanič. Prijateljstvo nastalo 1898. godine razlog je što je dr Niko Zupanič jedan period svog života i rada proveo u Etnografskom muzeju u Beogradu (Bižić-Omčikus, 2003). Verujući u potrebu uključivanja (fizičke) antropologije u rad Etnografskog muzeja, Sima Trojanović je omogućio svom kolegi da započne rad u okviru ove naučne oblasti. Rešenjem Ministarstva Prosvete Kraljevine Srbije od 30. jula 1913. godine, Niko Zupanič je postavljen za kustosa Etnografskog muzeja, sa naročitim zadatkom da se posveti „u prvom redu merenju živog i mrtvog materijala ranijih i današnjih stanovnika Srpske države i onih oblasti u kojima naš narod živi“.. ${ }^{1}$

Niko Zupanič je radio kao kustos u antropološko-paleontološkom odeljenju Etnografskog muzeja u Beogradu od 1913. do 1921. godine. U Ljubljanu se preselio da bi postavio etnološke i antropološke kriterijume za delovanje Etnografskog Inštituta, koji je osnovan upravo 1921. godine. Po formiranju Kraljevog etnografskog muzeja u Ljubljani g. 1923, kasnije nazvanog Etnografski muzej u Ljubljani, a danas - Slovenski etnografski muzej (SEM), postavljen je za njegovog prvog upravnika. Odlazeći iz Beograda, poneo je predmete koje je nabavljao u Srbiji, a najviše u Šapcu, rodnom mestu Sime Trojanovića. Poneo je i staklene negative snimaka sa svojih putovanja po Srbiji, koji se od tada nalaze u Dokumentaciji Slovenskog etnografskog muzeja.

${ }^{1}$ Arhiv Narodnog muzeja, br. 233.

$$
104
$$


V. Bižić-Omčikus

Srbija u SEM-u, Slovenija u EM-u

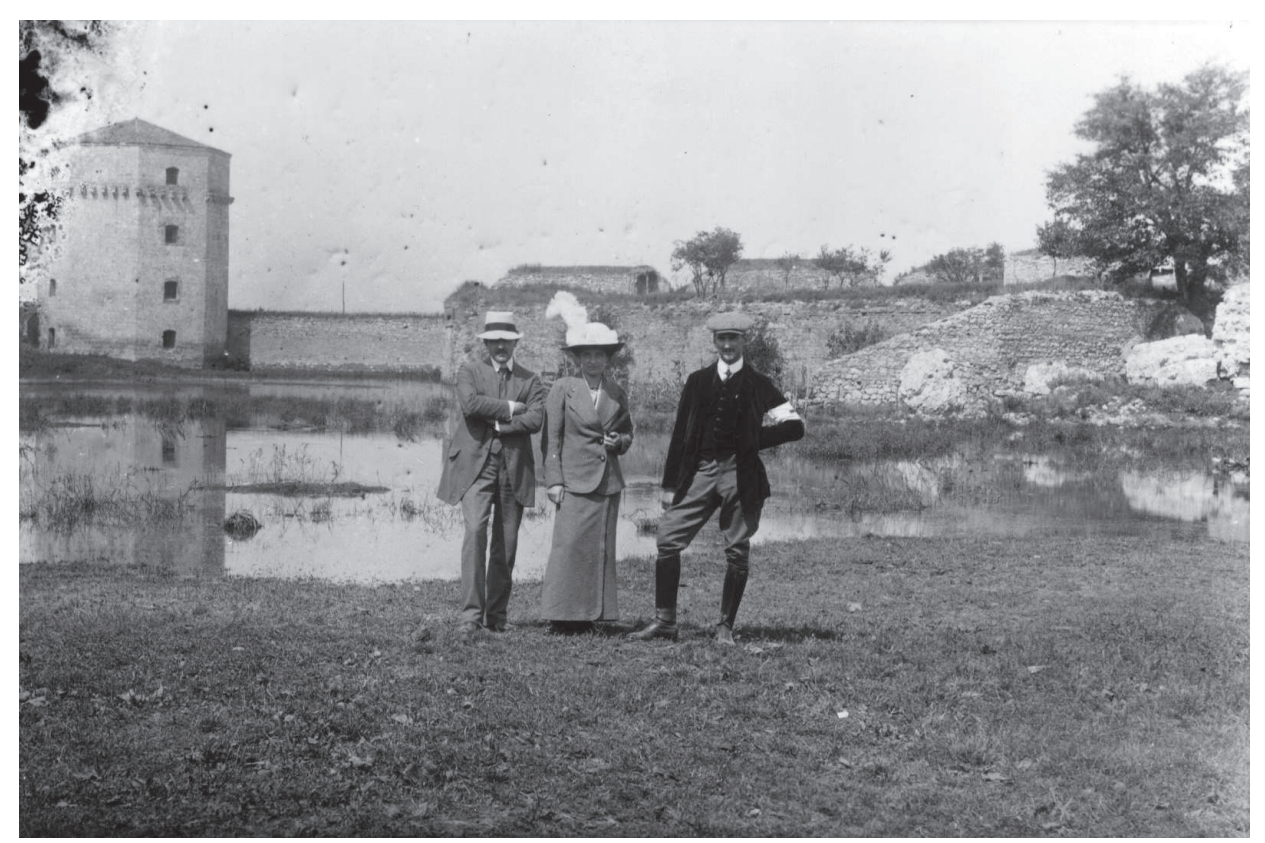

Niko Zupanič (prvi sleva) s prijateljima kod Kule Nebojše u Beogradu, 1913. godina. (Dokumentacija SEM)

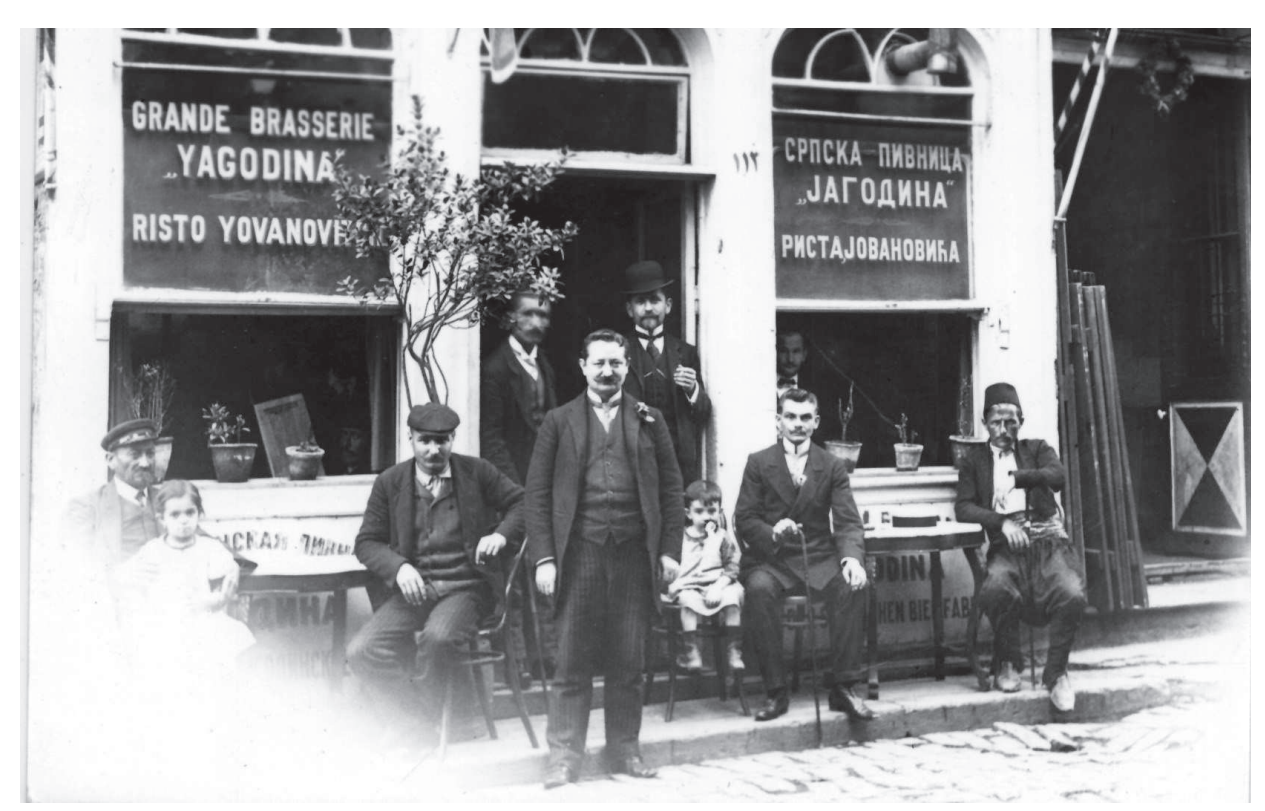

Fotografija koju je Niko Zupanič snimio putujući po Srbiji. (Dokumentacija SEM) 
Od srpskih kulturnih dobara, osim predmeta nabavljenih posredstvom dr Nika Zupaniča, u SEM-u se nalazi i zbirka keramike iz Pirota (27 predmeta), koju je SEM otkupio na Ljubljanskom velesajmu 1932. godine, kao i predmeti koje su različiti kolekcionari prodavali Muzeju. U Knjigu ulaza muzejskih predmeta za godine od 1965. do 1976, s datumom 18. avgust 1968, upisano je da je Dragutin M. Đorđević, sveštenik iz Leskovca, prodao Muzeju sedam maski „koruba“, četiri maske „lejka“i šest sablji s koricama.

SEM poseduje ukupno 185 predmeta srpskog porekla, među kojima su i delovi narodnih nošnji i nakita iz Šumadije i Šapca, iz okoline Peći i iz Gračanice. Pretpostavlja se da ih je nabavio Niko Zupanič putujući sa Simom Trojanovićem po Srbiji.

Predmeti su dobro obezbeđeni; nalaze se u metalnim ormanima, zaštićeni od provale, štetnih isparenja, vlage, požara. U podzemnim prostorijama, gde je smešten kompletan muzejski depo, održava se temperatura vazduha od $19^{\circ} \mathrm{C}$ i vlažnost od $45 \%$ do $55 \%$, i preduzete su znatne mere preventivne zaštite.

Etnografska dobra srpskog porekla u vlasništvu Slovenskog etnografskog muzeja $u$ Ljubljani pregledana su i dokumentovana $u$ okviru autorskog projekta „U potrazi za rasutim srpskim etnografskim blagom / Srpska etnografska dobra u rasejanju“ oktobra 2008. godine, zahvaljujući razumevanju i materijalnoj podršci Ministarstva za dijasporu Republike Srbije (Bižić-Omčikus 2009, 331).

\section{„Slovenija“ u Etnografskom muzeju u Beogradu}

U Etnografskom muzeju u Beogradu čuva se 246 predmeta poreklom iz Slovenije. Svi ovi predmeti potiču iz Gorenjske (29), Dolenjske (14), Bele Krajine (11), Štajerske (2), iz nekadašnje Kranjske (1) ${ }^{2}$ i iz nepoznatih mesta u Sloveniji (189).

Različiti su načini na koje je Etnografski muzej u Beogradu nabavljao predmete iz Slovenije. Najčešće su bili otkupljivani, ali poneki je dobijen i na poklon. Prema podacima koji se čuvaju u Etnografskom muzeju u Beogradu, prvi otkupljeni predmet iz Slovenije je kutija za palidrvca (inv. broj 9102), koju je nabavio prvi upravnik Etnografskog muzeja dr Sima Trojanović 1906. godine. Zatim su on i njegov saradnik Nikola Zega kasnijih godina otkupili još nekoliko predmeta, da bi novi veći otkupi, i to uskršnjih jaja (27 primeraka),

\footnotetext{
${ }^{2}$ Kranjski istorijski pejzaž obuhvatao je tri današnje slovenačke pokrajine - Gorenjsku, Dolenjsku, Notranjsku, kao i delove primorske regije.
} 
V. Bižić-Omčikus

Srbija u SEM-u, Slovenija u EM-u

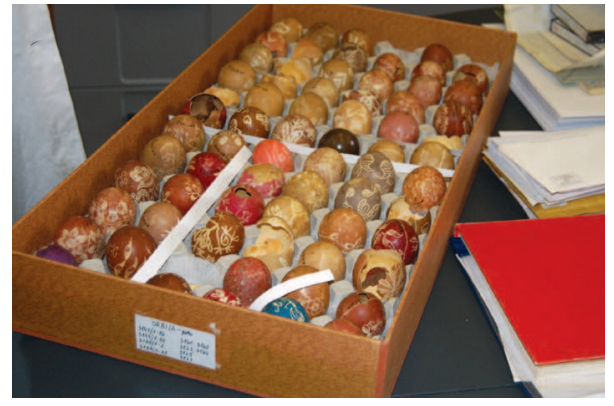

Uskršnja jaja iz Srbije,

nabavio N. Zupanič 1918. godine. (Foto:Vesna Bižić-Omčikus, 2008. godina)

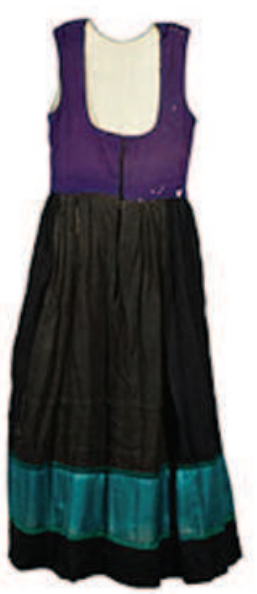

Haljina (EM, inv. broj 42056)

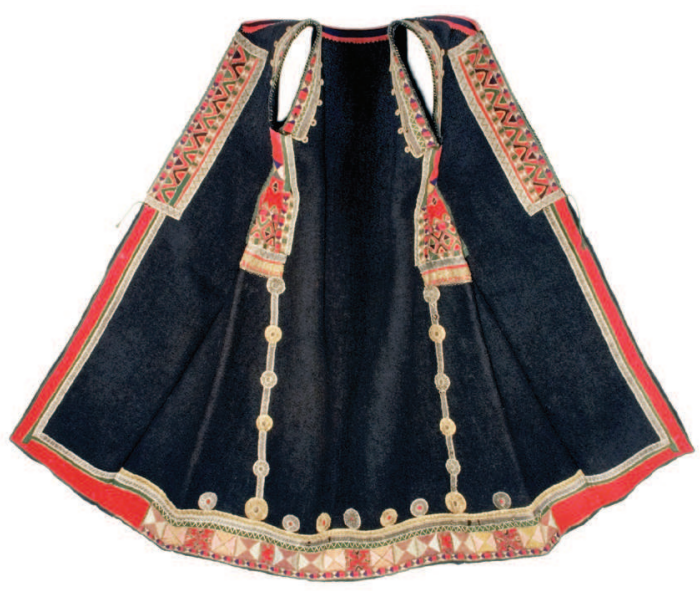

Zubun (EM, inv. broj 42038)

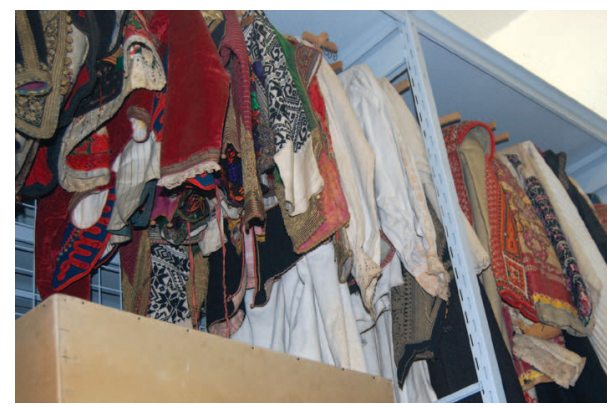

Delovi narodne nošnje iz Srbije u zbirci Slovenskog etnografskog muzeja. (Foto: Vesna Bižić-Omčikus, 2008. godina)

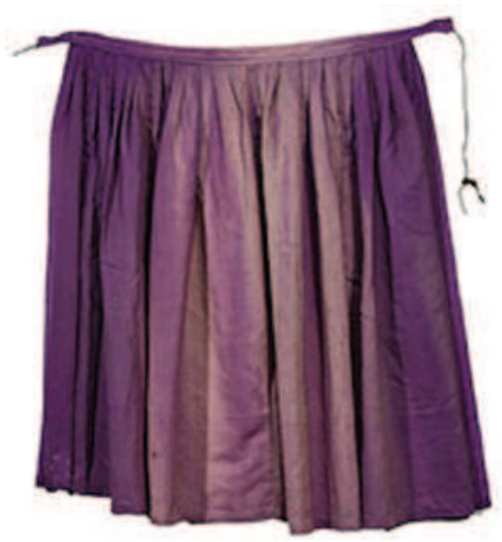

Pregača (EM, inv. broj 42057)

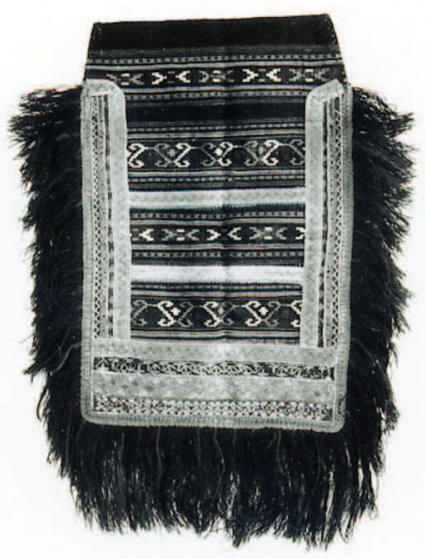

Pregača (EM, inv. broj 33323) 
usledili 1924. i 1928. godine. U to vreme je Borivoje Drobnjaković, tadašnji direktor Muzeja, otkupio 30 različitih predmeta, uglavnom iz Maribora i Metlike.

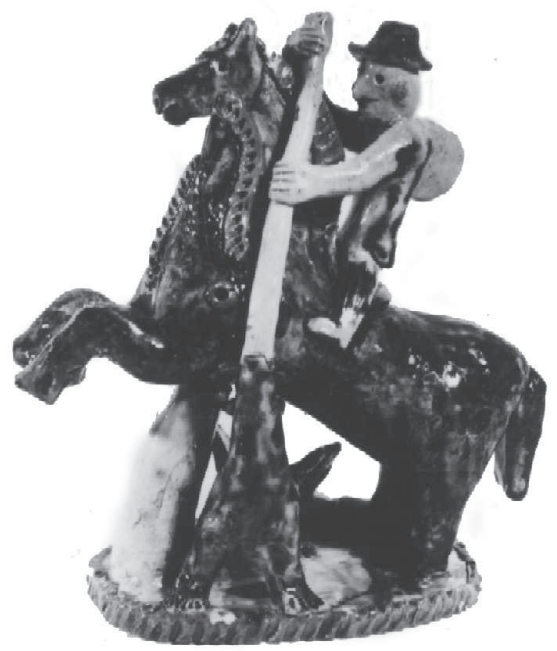

Sv. Jurij - Izradio „lončar“ Polde Bojc iz Dolenje Vasi 1968. godine. (EM, inv. broj 9846)

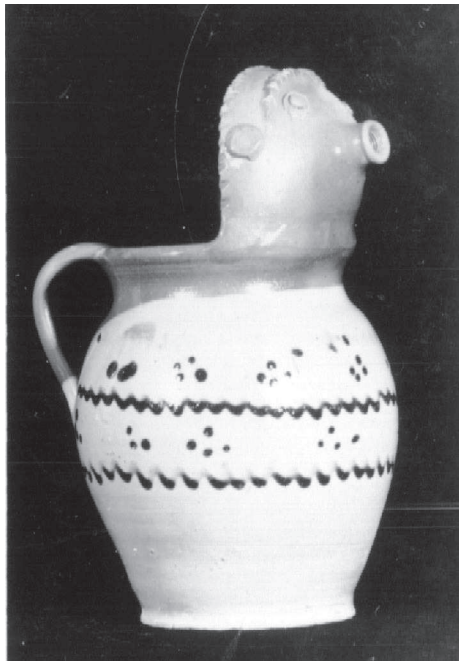

Bokal Sova - Izradio Leopold Kržan iz Novog Mesta 1968. godine. (EM, inv. broj 9853)

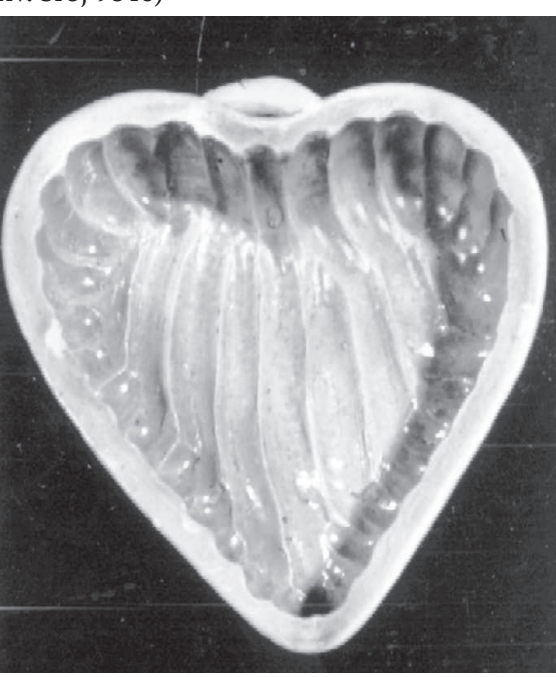

Modla Srce - Izradio Adolf Hašaj iz Murske Sobote 1968. godine. (EM, inv. broj 9856)

Etnografska kulturna dobra poreklom iz Slovenije svrstana su u zbirke: Narodne nošnje Slovenije, Vez i čipka, Nakit, Keramika, Predmeti uz običaje, Narodna znanja i verovanja, Pokućstvo, Posuđe, Zemljoradnja, Voćarstvo i vinogradarstvo i Tekstilne sprave i pomagala. 


\section{Bižić-Omčikus \\ Srbija u SEM-u, Slovenija u EM-u}

Najveći broj predmeta pripada zbirci keramike: bokali, ćupovi, testije, činije, različite figure i modle, njih ukupno osamdeset četiri. Keramika je otkupljena šezdesetih godina XX veka, na Sajmu lončarstva koji je 30. maja 1968. godine organizovao Etnografski muzej u Ljubljani. U dokumentaciji Etnografskog muzeja u Beogradu zabeležena su i imena majstora, odnosno prodavaca.

U Etnografskom muzeju u Beogradu, druga po brojnosti predmeta iz Slovenije je zbirka pod nazivom Narodne nošnje Slovenije. Sastoji se od 54 odevna predmeta, koji su izrađivani od 30-ih godina XIX veka do prve polovine XX veka. Osim pojedinačnih delova, postoje tri kompleta ženske nošnje iz mesta Rateče, Moste i Ziljska Dolina. U saradnji sa Slovenskim etnografskim muzejom, 1983. godine su u Etnografskom muzeju u Beogradu izrađene rekonstrukcije tri kompleta ženske nošnje iz Rateče i Bele Krajine, kao i muškog kompleta letnje nošnje iz Bele Krajine (Šarac-Momčilović 2012, 244).

Najstariji predmeti u ovoj zbirci - haljina (EM, inv. broj 42056) i pregača (EM, inv. broj 42057), otkupljeni 1931. godine od prof. Bohinjca iz Ljubljane, potiču iz prve polovine XIX veka.

Većina predmeta je iz druge polovine istog veka. Uglavnom su nošeni u svečanim prilikama - pri odlasku u crkvu, na venčanja, ili u posete. Najveći broj (49) pripada kulturi odevanja stanovništva slovenačke nacionalnosti $\mathrm{i}$ katoličke veroispovesti, dok su pet predmeta (zubun, pregača i tri kape) izradili pripadnici srpske nacionalnosti i pravoslavne veroispovesti iz mesta Bojanci i Otok u Beloj Krajini. ${ }^{3}$

Nošnje iz ove zbirke prikazivale su narodnu kulturu Slovenije na dve stalne izložbe Etnografskog muzeja u Beogradu: „Umetnost naroda Jugoslavije“ (od 1961. do 1976.) i „Narodne nošnje Jugoslavije“ (od 1976. do 1984.)4, a gostovale su u Australiji 1988. godine, u okviru posebno pripremljene izložbe „Narodne nošnje Jugoslavije“.5

Zbog svoje autentičnosti, načina izrade, starosti, ali i očuvanosti, zubun i pregača iz Bele Krajine svrstani su u grupu predmeta najviše - A kategorije.

Zubun iz nepoznatog mesta u Beloj Krajini, koji je nabavio Sima Trojanović 1913. godine, od crnog je sukna, bez rukava, dužine do ispod kolena, otvoren spreda celom dužinom, krojen od jedne po-

\footnotetext{
${ }^{3}$ Podaci o predmetima preuzeti su iz Centralnog registra predmeta Etnografskog muzeja u Beogradu.

${ }^{4}$ Jasna Bjeladinović-Jergić, Narodne nošnje Jugoslavije, Etnografski muzej, Beograd 1976.

${ }^{5}$ Tatjana Zec, Narodne nošnje Jugoslavije, katalog izložbe, Vologong 1988.
} 
le presavijene na ramenima, i proširen bočnim klinovima od struka naniže. Ukrašen je duž svih rubova i po klinovima aplikacijama zlatnog i srebrnog širita i gajtana, zelenog vunenog gajtana, trakama i komadićima crvene, zelene i modre čoje, složene u šire trake i vezene raznobojnim svilenim koncem (belim, žutom, smeđim, zelenim, plavim). Ornamentika je geometrijska - cik-cak, trouglovi složeni u kvadrate. Činio je deo svečane nošnje. (EM, inv. broj 42038)

Pregača iz Črnomlja, nabavljena 1910. Izrađena je od vune mrke boje, sa poprečnim paralenim prugama izvedenim u tkanju. Izdvajaju se četiri pojasa sa stilizovanim geometrijskim šarama, crvene, modre i bele boje. Između njih su paralelne uže pruge od modre, bele i žute vune. Na bočnim ivicama su aplikacije (u nekoliko redova) od crvene, mrke i zelene čoje, sa stilizovanim biljnim i geometrijskim motivima, izvezenim raznobojnim pamučnim koncem (žute, plave, smeđe i bele boje). Ivice su ukrašene resama od mrke, zelene, crvene i plave vune. (EM, inv. broj 33323)

\section{Zaključak}

Prisustvo predmeta jednog naroda u muzejima izvan države nastanka ukazuje na kulturne veze koje su se u prošlosti uspostavljale i negovale, a često su bile i odraz ličnog prijateljstva, s obzirom na to da nabavke nisu bile planirane, a istraživanja sistematski organizovana.

U novoj sredini, ovi muzejski predmeti dobili su novi život, postali su svojevrsni ambasadori kulture svog naroda. Ukoliko su institucionalni kontakati prestali, ti predmeti su ostajali kao zametak za obnavljanje saradnje.

U vremenu u kome živimo, s vrlo razvijenim tehničkim, tehnološkim mogućnostima i brzom razmenom informacija, čini se da više nije ni važno gde će se etnografsko blago čuvati. U zemlji matici, iz koje su predmeti izneseni, nužno je da postoji iscrpna dokumentacija o nasleđu u dijaspori, o njegovom stanju očuvanosti, o preventivnim i tehničkim merama zaštite koje se preduzimaju da bi kulturno dobro nastavilo sa svojim životom izvan zemlje porekla. Etnografska baština u dijaspori predstavlja neku vrstu istorijske niti koja povezuje kulture evropskih naroda, i zahvaljujući njoj, postoji mogućnost da se na početku XXI veka rekonstruišu događaji iz dalje prošlosti. Stoga je svaki podatak o nasleđu u rasejanju važan i za sadašnje, ali i za buduće istraživače narodne kulture i nacionalnog identiteta. 


\section{Bižić-Omčikus}

Srbija u SEM-u, Slovenija u EM-u

Arhivska građa

Arhiv Narodnog muzeja. Rešenje Ministarstva Prosvete Kraljevine Srbije od 30. jula 1913, br. 233.

Literatura

Bižić-Omčikus, Vesna. 2002. „Dr Sima Trojanović - život i rad“.U Na početku: dr Sima Trojanović, istraživač, naučnik i prvi čuvar Etnografskog muzeja, ur. Vesna Bižić-Omčikus, 7 - 82. Beograd : Etnografski muzej Srbije.

Bižić-Omčikus, Vesna. 2003. Niko Županič v Etnografskem muzeju v Beogradu. Etnolog: glasnik Slovenskega etnografskega muzeja 13 (64) : $273-283$.

Bižić-Omčikus, Vesna. 2009. Etnografski materijal poreklom iz Srbije u Slovenskom etnografskom muzeju u Ljubljani. Glasnik Etnografskog muzeja u Beogradu 73 : 327 - 333.

Bjeladinović-Jergić, Jasna. 1976. Narodne nošnje Jugoslavije. Beograd : Etnografski muzej.

Zec, Tatjana. 1988. Narodne nošnje Jugoslavije, katalog izložbe.

Šarac-Momčilović, Vera. 2012. Zbirka narodnih nošnji Republike Slovenije u Etnografskom muzeju u Beogradu. Glasnik Etnografskog muzeja 76 : $243-260$.

Vesna Bižić-Omčikus

Etnografski muzej v Beogradu

Srbija

vesna.omcikus@etnografskimuzej.rs

\section{SRBIJA V SEM-U, SLOVENIJA V EM-U}

V tekstu Srbija v SEM-u, Slovenija v EM-u so pojasnjene migracije predmetov iz Srbije, ki se danes nahajajo v Slovenskem etnografskem muzeju v Ljubljani, kot tudi predmetov iz Slovenije, ki se nahajajo v Etnografskem muzeju v Beogradu. Enako kot ljudje so se tudi predmeti skupaj s svojimi lastniki selili v razne kraje Evrope in sveta, tako tudi iz Slovenije v Srbijo in iz Srbije v Slovenijo. Ko so prispeli v novo okolje, so iz zasebne lastnine prek daril ali odkupov postajali del muzejskih zbirk oziroma kulturne dobrine, dostopne javnosti. S premikanjem predmetov so se medsebojno prežemale kulture narodov, ki so jih izdelali, z uvrstitvijo $\mathrm{v}$ muzeje pa so ti predmeti postali predstavniki svojih kultur in narodov v novem okolju.

Ključne besede: Srbija, Slovenija, Etnografski muzej v Beogradu, Slovenski etnografski muzej, etnografske kulturne dobrine, predmeti 


\author{
Vesna Bižić-Omčikus \\ Ethnographic Museum in Belgrade \\ Serbia \\ vesna.omcikus@etnografskimuzej.rs
}

\title{
SERBIA IN THE SEM, SLOVENIA IN THE EM
}

The text Serbia in the SEM, Slovenia in the EM explains the migrations of objects from Serbia that are presently part of the collections of the Slovenian Ethnographic Museum (Ljubljana), as well the migration of objects from Slovenia that are currently held by the Ethnographic Museum in Belgrade. Just like people, the items moved, together with their owners, to various parts of Europe and the world, and they also moved from Slovenia to Serbia and vice versa. In the new environment, through gifts and purchase, they passed from the hands of private owners to museum collections, i.e. they became publicly available cultural assets. Through migration of objects the cultures of the nations who created them permeated each other, and by becoming part of museum collections these objects became representatives of their cultures and nations in new environments.

Keywords: Serbia, Slovenia, Ethnographic Museum in Belgrade, Slovenian Ethnographic Museum, ethnographic cultural assets, objects 